\title{
Paulin d'Aumale, Traité du pur amour (1695-1699)
}

Grenoble, Jérôme Millon, 2015,148 p.,texte présenté et annoté par Christian Belin

Daniel Vidal

\section{OpenEdition}

12 Journals

Édition électronique

URL : http://journals.openedition.org/assr/28178

DOI : $10.4000 /$ assr.28178

ISSN : $1777-5825$

Éditeur

Éditions de l'EHESS

\section{Édition imprimée}

Date de publication : 31 décembre 2016

Pagination : 259

ISSN : 0335-5985

\section{Référence électronique}

Daniel Vidal, «Paulin d'Aumale, Traité du pur amour (1695-1699) », Archives de sciences sociales des religions [En ligne], 176 | octobre-décembre 2016, mis en ligne le 13 juillet 2017, consulté le 24 septembre 2020. URL : http://journals.openedition.org/assr/28178; DOI : https://doi.org/10.4000/ assr.28178

Ce document a été généré automatiquement le 24 septembre 2020.

(c) Archives de sciences sociales des religions 


\section{Paulin d'Aumale, Traité du pur amour (1695-1699)}

Grenoble, Jérôme Millon, 2015,148 p.,texte présenté et annoté par Christian Belin

\section{Daniel Vidal}

\section{RÉFÉRENCE}

Paulin d'Aumale, Traité du pur amour (1695-1699), Grenoble, Jérôme Millon, 2015,148 p.,texte présenté et annoté par Christian Belin

1 Si le xvir e siècle fut le siècle de "l'invasion mystique ", celle-ci connut son éclat le plus lumineux, en même temps que son affirmation la plus complexe à assumer, dans le «système » du pur amour, et dans sa formulation la plus radicale. On rappellera pour mémoire, d'un bout à l'autre du siècle, et pour aller à l'essentiel, le Traité de l'amour de Dieu de François de Sales (1616), La clef du pur amour d'Alexandre Piny (1681, encore faudrait-il évoquer l'ensemble de son œuvre), et le grand œuvre de Fénelon en toute fin de siècle (rappelons également l'ouvrage essentiel de Jacques Le Brun, Le pur amour de Platon à Lacan, Paris, Seuil, 2002). C'est en cette même fin, et dans les tourmentes de la controverse ranimée par le quiétisme, que fut rédigé en 1695-1699 le Traité du pur amour par Paulin d'Aumale, tiercelin du couvent de Nazareth, qui fut quelque temps confesseur de Jeanne Guyon, le temps, précisément, de se laisser convertir à la «science » d'amour pur, par la grande mystique dont il avait la charge spirituelle. Par un ensemble gradué de «demandes » relevant d'un cadre dogmatique traditionnel, et d'un exposé des réponses venues de l'expérience intime et singulière de l'auteur ou d'un «sujet» surpris dans son existence sensible et quotidienne, ce «manuscrit insolite», que Christian Belin réédite et commente, prend valeur théorique et "pragmatique» de la mise au net d'une "conviction à transmettre en urgence». Comme il en va de toute révélation qui vient d'être éprouvée, et dont il faut, en urgence en effet, témoigner. 
2 Et d'abord, de ceci : que l'énoncé du pur amour ne s'entend que comme mouvement en quelque sorte interne à l'amour principiel, essentiel, de Dieu, et comme en réciprocité exacte avec lui. Mais cette « infusion divine » de l'amour suppose, pour y répondre, et s'y soumettre, un acte insurrectionnel de la « créature » contre son «moi », ses désirs, ses "propriétés ». Le pur amour est cet échange de soi contre Dieu, ce " Tout-Autre ", pour reprendre le point central des travaux contemporains sur la mystique. Échange effectué au revers de toute économie comptable, dans la gratuité qui fonde tout rapport absolu à Dieu. De là la passion de désappropriation de soi, la volonté (volo) de se perdre à l'infini dans le mouvement qui rapproche de la divinité, et d'en finir avec ce «moi » que Pascal dit «haïssable». Car il faut mobiliser toute cette haine de soi pour que "l'impureté radicale de l'homme », commente l'auteur, puisse faire place nette au seul amour de Dieu. Mais il faut témoigner aussi de ce qui qualifie le pur amour comme «sujet le plus impossible qui soit». Si l'amour pour Dieu est un amour qui vient de Dieu, d'emblée le sujet est confronté à un défi insoutenable: l'amour auquel il doit atteindre est déjà en lui déposé, et son assomption en son dieu ne peut s'entendre que comme une coïncidence toujours différée. Sauf à se prétendre dieu soi-même. D'emblée, le pur amour définit un horizon impossible, et c'est bien en cela qu'il est cet "état mobile» qu'analyse l'auteur, et cette "course paroxystique sans fin ", qui projette le sujet vers toujours plus de défaites de soi, de mises à néant de son amourpropre, et de pertes de tout ce qui relève d'une affectivité dévorante. Car la "purification " n'est jamais aboutie, et se dire d'amour pur est aussitôt ne pouvoir penser telle pureté que dans le rapport nécessaire avec l'impureté dont il se veut le contraire et qui pourtant sans cesse le hante comme son ombre nécessaire.

Le pur amour est, en spiritualité, un combat pour ainsi dire perdu d'avance, mais cette perte même en est sans doute la chance paradoxale. Car il ne se peut que dans la confrontation entre deux exigences, que rappelle l'auteur: échapper à toute «contamination " avec le monde sensible des sentiments et de l'« eros »; échapper à toute « abstraction» dogmatique ou de conceptualité en ses schèmes, ses artifices, ses constructions. Entre ces deux écueils, la quête et l'affirmation du pur amour procède à partir (et partir est ici le mot qui convient) de soi-même, comme d'un lieu qu'il faut à tout moment tenir à perte de vue, et habiter pleinement le vide ainsi offert, et où Dieu, sans doute, peut alors se dire. Comment ne le pourrait-il pas, quand sa grâce est d'emblée au commencement de la quête, et participe de son déploiement. Elle est ce déploiement même. L'auteur rappelle que, pour les quétistes, «le processus contemplatif lui-même relève exclusivement de la grâce ». Cette gratuité est l'autre nom de cette pureté à quoi tout "spirituel » veut atteindre, et s'y perdre. Mais au-delà de tout ce qui se consomme de techniques et de postures, de corps et d'âme, dans cette recherche d'amour pur, il est d'autres contraintes, quant à l'écriture de cet amour et de sa pureté, et dans le verbe qui le dit. «Pur » est le signifiant par excellence qui, selon la formule de l'auteur, « isole lexicalement » l'amour qu'il qualifie. En ce sens, il doit être pris « absolument », étant en effet le « lieu » même de «l'absolu divin ». Dire « pur » est dire Dieu, en son immédiateté. L'énonciation est l'acte même. L'acte est pur, Dieu est l'acte. L'auteur relance un ensemble de réflexions dans la suite des travaux de Michel de Certeau, sur la langue mystique, et sa performativité.

4 Il se passe en effet cet événement remarquable, en mystique d'amour pur, que par l'extrême affranchissement de soi, à quoi se voue le spirituel, par la radicalité de la mise en perte de soi à laquelle il se livre, par désappropriation du monde des valeurs et 
des positivités, par cette "démotivation » qui en est la figure essentielle, pour cet ensemble de dépossessions, le verbe doit à son tour se libérer de toute discursivité. Contre l'impureté constitutive de tout discours sur le pur amour, puisqu'en rapport obligé au "monde ", à la subjectivité, à la pesanteur de "l'être ", sinon sa légèreté, Paulin d'Aumale, dans son Traité, revendique cette «abstraction ascétique » du verbe, seule capable de dire l'absolu. Ainsi en va-t-il, remarque l'auteur, de la poésie du désert, dont l'aridité devient «indice de pureté ». Et ce n'est pas le moindre intérêt de cette lecture du pur amour, que de signaler combien le "discours » mystique, par "l'ascèse " qu'il requiert, entre en résonance avec la raison poétique. Si telle comparaison se peut, c'est qu'en l'un et l'autre cas, pour des raisons qu'il conviendrait d'interroger plus à fond, il s'agit de placer « l'absolu à portée de mains », en prenant décidément le parti, en poésie, des «choses » et, en mystique, de ce que Belin nomme leur «banalité », cet autre nom de leur nudité. 